\title{
THE USE OF MIXED METHODS RESEARCH IN THE FIELD OF BEHAVIOURAL SCIENCES
}

\section{OLATZ LOPEZ-FERNANDEZ ${ }^{1}$}

Department of Methodology of Behavioural Sciences, Faculty of Psychology, University of Barcelona

\section{JOSE F. MOLINA-AZORIN}

Department of Management, Faculty of Economics and Business, University of Alicante

\begin{abstract}
Mixed methods research involves the combined use of quantitative and qualitative methods in the same research study, and it is becoming increasingly important in several scientific areas. The aim of this paper is to review and compare through a mixed methods multiple-case study the application of this methodology in three reputable behavioural science journals: the Journal of Organizational Behavior, Addictive Behaviors and Psicothema. A quantitative analysis was carried out to review all the papers published in these journals during the period 2003-2008 and classify them into two blocks: theoretical and empirical, with the latter being further subdivided into three subtypes (quantitative, qualitative and mixed). A qualitative analysis determined the main characteristics of the mixed methods studies identified, in order to describe in more detail the ways in which the two methods are combined based on their purpose, priority, implementation and research design. From the journals selected, a total of 1.958 articles were analysed, the majority of which corresponded to empirical studies, with only a small number referring to research that used mixed methods. Nonetheless, mixed methods research does appear in all the behavioural science journals studied within the period selected, showing a range of designs, where the sequential equal weight mixed methods research design seems to stand out.
\end{abstract}

\section{Keywords}

Mixed methods research, Quantitative and qualitative methods, Research design, Behavioural sciences

\footnotetext{
${ }^{1}$ Corresponding author:

Olatz Lopez-Fernandez, Dept. Metodologia de les Ciències del Comportament, Facultat de Psicologia, Universitat de Barcelona. Passeig Vall d'Hebron, 171. Barcelona, 08035 (Spain).

E-mail address: olatzlopez@ub.edu Telephone: 0034933125074 Fax number: 0034934021359
} 


\section{Introduction}

The combination of quantitative and qualitative research methods in the same study, i.e. the use of mixed methods, is taking on greater importance (Tashakkori and Teddlie, 1998, 2003; Creswell, 2003). Although it started during the 1960s as a concept of mixing both main research methods (Leech and Onwuegbuzie, 2009), it has increased considerably over the last fifteen years in many disciplines, despite being criticized for violating quantitative and qualitative paradigmatic assumptions (Sale and Brazil, 2004). This methodological approach starts from the premise that it is often not necessary to choose between the two traditional strategies (quantitative versus qualitative), the idea being that it can be more fruitful to consider how the strengths of each can be combined within a mixed approach. As such, the use of mixed methods may play an important role in research, since the results obtained via the different methods can enrich and improve our understanding of the matters under study and foster fresh ideas about them, in order to give answers to questions that are difficult to answer by a sole classical method (quantitative or qualitative).

Creswell and Plano Clark (2007) note that the application and use of mixed methods has only been reviewed in a small number of disciplines, and it is therefore of interest to examine how it is being used in others. In this context the present study sought to analyse the use of mixed methods in the behavioural sciences, examining principally the specific designs used and the stated purposes of the studies that have used this approach and which have been published in three journals of reference in various fields of the behavioural sciences: the Journal of Organizational Behavior, Addictive Behaviors and Psicothema.

The paper is structured as follows. The next section describes several general aspects of the mixed methods approach, highlighting the main designs that can be used and the purposes which are usually sought. The following section describes the methodology used in carrying out the literature review and identifying the published studies that used mixed methods. The results section reports the main characteristics of these studies in each of the journals analysed. Finally, the results obtained are compared and a number of recommendations are made as regards future research. 


\section{Mixed methods research}

The application of mixed methods research is on the rise in many disciplines. Some authors regard this approach as the third methodological movement (Tashakkori and Teddlie, 2003), one which complements purely quantitative or qualitative strategies. Indeed, mixed methods research has been the subject of books, articles and special editions of journals (see, for example, Morse, 1991; Morgan, 1998; Tashakkori and Teddlie, 1998, 2003; Creswell, 2003; Forthofer, 2003; Rallis and Rossman, 2003; Rocco et al., 2003; Ivankova, Creswell and Stick, 2006; Creswell and Plano Clark, 2007; Greene, 2007; Bergman, 2008; Teddlie and Tashakkori, 2009; Onwuegbuzie, Johnson and Collins, 2009; Plano Clark, Garrett and Leslie-Pelecky, 2010). Moreover, a number of journals focused specifically on mixed methods have appeared in recent years (Journal of Mixed Methods Research and the International Journal of Multiple Research Approaches). Studies based on this methodology include key words, typologies and purposes associated with mixed designs, and knowledge of these can make it easier to analyse these designs within behavioural sciences.

There are two main factors which can help determine the various types of mixed methods design (Morse, 1991; Morgan, 1998; Tashakkori and Teddlie, 1998; Creswell, 2003; Onwuegbuzie, Johnson and Collins, 2009):

- Priority/weight/emphasis of approaches. In a mixed methods study the researcher can give the same priority, weight or status to the quantitative and qualitative aspects (equal weight designs), or alternatively may give greater weight to one of them (different weight designs).

- Implementation of data collection/time orientation. This refers to the order in which the researcher collects quantitative and qualitative data. The two options are collecting information at the same time (simultaneous, concurrent or parallel designs) or obtaining data at different points (sequential or two-stage designs).

The way in which these two factors are combined will determine the resulting design. The notation proposed by Morse (1991) is useful for representing the different possible designs. In her system the abbreviations "quan" and "qual" are used to represent the quantitative and qualitative parts, respectively. When one method has greater weight than the other the former is shown in capitals letters (QUAN, QUAL), while the latter is written in lower case (quan, qual). Furthermore, the symbol "+" is used to indicate a 
simultaneous design, whereas the arrow " $\rightarrow$ " refers to a sequential design. Therefore, the various combinations of data collection strategy and priority produce four blocks that give rise to nine mixed methods designs (Johnson and Onwuegbuzie, 2004):

(a) Equal weight, simultaneous: (1) QUAL+QUAN.

(b) Equal weight, sequential: (2) QUAL $\rightarrow$ QUAN; (3) QUAN $\rightarrow$ QUAL.

(c) Different weight, simultaneous: (4) QUAL+quan; (5) QUAN+qual.

(d) Different weight, sequential: (6) qual $\rightarrow$ QUAN; (7) QUAL $\rightarrow$ quan; quan $\rightarrow$ QUAL; (9) QUAN $\rightarrow$ qual.

As regards the purpose of conducting mixed designs by integrating different types of data in the same study, several potential reasons have been noted by various authors (Greene, Caracelli and Graham, 1989; Morgan, 1998; Creswell, 2003). Two of the most widely stated reasons are triangulation and complementarity. The main aim of triangulation (Jick, 1979) is to achieve a convergence of the results obtained via the quantitative and qualitative approaches, such that these results are more reliable. What is sought, therefore, is a corroboration or correspondence of results obtained through different methods. Regarding complementarity, the main objective is to clarify or illustrate the results obtained with one method by also applying the other. In this case the designs used are usually sequential, for example, a QUAN $\rightarrow$ qual design, whereby the qualitative part may help to evaluate and interpret the results obtained from the main quantitative study. Another potential purpose of mixed methods research is development. In this case it is again usual to use sequential designs, in which one of the methods (normally the one with least weight) helps in some way to improve upon the subsequent implementation of the other method (normally the main or dominant one). For example, in a qual $\rightarrow$ QUAN study the qualitative part could help to develop theory, propose hypotheses, improve the quantitative instrument used for data collection and/or describe better the context so as to select specific variables and measures. A further purpose of mixed methods designs may be to enable expansion, i.e. seeking to analyse and explore different facets of a phenomenon so as to obtain a richer and more detailed understanding of it. For example, the quantitative part of a study may focus on fixed characteristics of a phenomenon, while the qualitative part addresses dynamic or process aspects.

\section{Methods}




\subsection{Sampling scheme}

This study was a mixed methods research to analyze the types of research studies published in reputable journals in the behavioural science field, specifically mixed methods publications, following Onwuegbuzie and Leech (2009) framework to identify an optimal sampling design. Identical samples from three journals were selected, using a sequential design where the quantitative first phase informed the second qualitative phase in order to identify and analyse the mixed methods designs used and the purposes being sought in this field. We conducted a literature review of the articles published in three peer-reviewed journals of reference covering different topics in this field: the Journal of Organizational Behavior, Addictive Behaviors and Psicothema. All articles published between 2003 and 2008 were used as our data, in order to determine the number of mixed methods studies that appeared during this period. The year 2003 is significant in the development of the mixed methods approach as it saw the publication of Tashakkori and Teddlie's Handbook of Mixed Methods in Social and Behavioral Research, which brought greater visibility and credibility to this approach.

\subsection{Research design}

Adapting Leech and Onwuegbuzie (2009) three-dimensional typology of mixed methods designs, our study was a partially mixed sequential equal status multiple-case study design (P3). It was considered as partially because it does not involve qualitative and quantitative research across all the research process components. In fact the quantitative and qualitative analyses were done separately. Besides the study has been considered a multiple-case study following Yin's case study approach (1993, 2003), for involving the choice of three journals (each one understood as single-case study) recognized as important in the behavioural science field, and treated equally in the same multiple subunits of analysis (the quantitative and qualitative ones) being an embedded case study. In the last step, the three study-cases were merged in a larger unit of analysis for their comparison. Specifically, in each single-case study (one journal), for the first quantitative phase a descriptive research design was used, detecting the following subunits of analysis: number of articles published per year, how many were non- 
empirical articles and how many were empirical ones (quantitative, qualitative and mixed-methods articles). Subsequently, in each single-case study (one journal), the second qualitative phase involved the following subunits of analysis: determine the purpose (triangulation, complementarity, development and expansion), the priority (equal or different weighs), the implementation (simultaneous or sequential) and the mixed-methods design (following notation proposed by Morse, 1991). Finally, in the current research it was expected that this partially mixed sequential equal status multiple-case study design will show a global picture of the mixed-methods designs more commonly used in the behavioural science field in these last years of publication.

\subsection{Analysis}

A Sequential Mixed Methods Analysis (SMMA; Onwuegbuzie and Teddlie, 2003; Tashakkori and Teddlie, 1998) was undertaken to analyze the research articles through analytic techniques in a sequential manner, in the quantitative and the qualitative phases described above. The purpose of this SMMA of a QUAN $\rightarrow$ QUAL design was development (Greene et al., 1989; Morgan, 1998; Creswell, 2003), whereby the results from the first quantitative method informed the use of the other method.

An important aspect related to the identification of mixed methods studies is the search strategy used. In this study, all articles published in the three journals were read and reviewed. This strategy has been used in some previous reviews (Niglas, 2004; Powell, Mihalas, Onwuegbuzie, Suldo and Daley, 2008; Hart, Smith, Swars and Smith, 2009). An alternative strategy is the use of a list of search terms for mixed methods studies that are entered into electronic databases and journal archives. This search strategy has been used by previous studies (Creswell, Fetters and Ivankova, 2004; Hanson, Creswell, Plano Clark, Petska and Creswell, 2005; Plano Clark, 2005; Bryman, 2006; Plano Clark, Huddleston-Casas, Churchill, O'Neil Green and Garrett, 2008). The use of these different search strategies may provide different results. In fact, Bryman (2006), using an electronic search, pointed out that this search strategy may provide a biased sample of mixed methods studies in the sense that by no means all authors of articles reporting mixed methods research foreground the fact that the findings reported derive from a combination of quantitative and qualitative research, or do not do so in terms of the key words that drove the online search strategy. In summary, the search strategy used to find 
mixed methods studies may influence the number of articles identified. Taking into account this important limitation of electronic search, we used the search strategy based on reviewing and reading all the articles published. In addition, this strategy enabled us not only to identify the mixed methods studies published, but also to classify all the articles into two broad groups, non-empirical and empirical, before sub-dividing the empirical studies into a further three categories: quantitative, qualitative and mixed. Having completed this classification the content of those articles reporting mixed methods was analysed, in each case determining the type of design used according to the priority and implementation assigned, as well as the main purpose of the study. All these aspects are described in the results section for each of the three journals, while the comparison between them is left for the discussion.

Mixed methods studies were normally identified through the information provided in the section of the paper referring to data collection and analysis. All the mixed methods studies were coded by the two authors (double coding) in order to determine their main characteristics as regards priority, implementation, type of design and purpose. The inter-coder reliability (measured by the percentage of agreement) was $80.5 \%$. Any discrepancies were discussed and resolved by consensus.

\section{Results}

\subsection{Journal of Organizational Behavior}

\subsubsection{Quantitative findings}

This is the most important journal in the specific field of organisational behaviour. Its impact factor for 2008 according to the JCR (SSCI) was 2.441. The main topics addressed in this journal are related to different aspects of individual and group psychology and behaviour within organisations, with a frequent emphasis on how these aspects may influence the performance and profitability of companies. The most important research topics addressed include motivation, leadership, job satisfaction, the balance between professional and private life, work-related stress, the development of professional careers and the functioning of teams, among others.

As regards the research methods described in this journal there is a predominance of empirical studies using a quantitative methodology. Qualitative research is accepted, but 
constitutes a minority approach. It should also be noted that, to date, no review has been conducted of the mixed methods studies published by this journal. Table 1 shows the distribution of articles by year and classified according to the type of study. As this journal is published eight times a year the present analysis covered 48 numbers, in which a total of 318 articles were published.

Table 1

It can be seen in the table that there is again a clear predominance of empirical studies $(72.6 \%)$. Also as before, the majority of papers report using a quantitative methodology (62\% of all articles and $85.3 \%$ of empirical studies). In this case there was an equal number of qualitative and mixed methods articles (seventeen each).

\subsubsection{Qualitative findings}

Table 2 shows the main characteristics of the seventeen mixed methods studies that were identified. The table shows that seven of these mixed methods studies gave equal weight to the quantitative and qualitative parts, while in the remaining ten priority was given to the quantitative aspect. As regards the implementation of data collection, four studies used a simultaneous strategy and thirteen a sequential approach. Analysis of priority and implementation in combination revealed empirical studies in three of the four main designs. Specifically, four articles reported a design of equal weight and simultaneous data collection (QUAL+QUAN), three used equal weight and a sequential strategy (two QUAN $\rightarrow$ QUAL and one QUAL $\rightarrow$ QUAN), and ten a design based on different weight and sequential implementation (seven qual $\rightarrow$ QUAN and three QUAN $\rightarrow$ qual). There were no designs involving different weight and simultaneous data collection.

Finally, as regards the purpose of using mixed methods the main objective (eight of seventeen studies) was development. The other stated purposes were, in descending order, complementarity (five studies), triangulation (three studies) and expansion (one study).

Table 2

\subsection{Addictive Behaviors}




\subsubsection{Quantitative findings}

This second journal was chosen due to it being one of the most widely recognised journals in the field of addictive behaviours at the international level. According to the JCR (SSCI) its impact factor for 2008 was 1.846. The journal focuses on human research in the area of substance abuse and includes both psychological and interdisciplinary studies. The most widely studied substances are alcohol and tobacco, among other drugs, and addictive behaviour is considered both in general and in specific groups (such as undergraduates, patients with a specific disorder, etc.).

As regards the predominant research methods that appear in this journal, quantitative empirical studies are once again the most common, with very little qualitative or mixed methods research being published. Table 3 shows the distribution of articles according to the same categories as were applied to the previous journal. In recent years this second journal has appeared monthly and thus, for the period studied, a total of 63 numbers were analysed, in which appeared 932 articles. As can be seen in Table 3, empirical articles accounted for $95.2 \%$ of those published, the large majority being quantitative in nature (94\% of the total and $98.8 \%$ of empirical studies).

Table 3

\subsubsection{Qualitative findings}

Table 4 shows the main characteristics of the six mixed methods studies that were identified. As regards priority, five of these studies gave equal weight to the quantitative and qualitative parts. In terms of the implementation strategy, four studies used a simultaneous and two a sequential approach. Specifically, the design of four studies was equal weight and simultaneous data collection (QUAL+QUAN), one study used equal weight and a sequential strategy (QUAL $\rightarrow$ QUAN) and one gave different weight to the two methods under a sequential design (QUAN $\rightarrow$ qual). There were no designs involving different priority and simultaneous data collection.

Finally, as regards the purpose of the mixed methods studies, three articles had the objective of triangulation and three, complementarity.

Table 4 


\subsection{Psicothema}

\subsubsection{Quantitative findings}

This is the most widely acknowledged journal in the field of the behavioural sciences in Spain. It features in the most important national and international scientific databases and the Journal Citation Reports (JCR) for 2008 give it an impact factor of 1.213 in the Social Science Citation Index (SSCI). The journal mainly publishes research articles, both basic and applied, in any area of psychology, regardless of the approach or theoretical orientation. However, the method and data analysis used must show rigour and contribute to the development of scientific knowledge in the discipline. The methodological topics that appear most often in the journal's articles are psychometrics, advanced statistics and research designs. As regards substantive topics in psychology, the journal has published a wide range of papers, including studies in clinical, developmental, educational and social psychology, as well as advances in new, more specific and innovative fields of psychology.

The analysis here revealed a predominance of empirical studies, which mainly used a quantitative methodology. Qualitative studies were in the minority, being similar in number to reports concerning mixed methods (Table 5).

\section{Table 5}

\subsubsection{Qualitative findings}

Table 5 shows this clear trend in favour of the quantitative approach and empirical studies. A number of general aspects should also be considered when interpreting this finding. Firstly, the journal is published quarterly (with an occasional annual supplement, as in the case of 2006), and there can be as many as thirty articles in each number. For the period studied here a total of 708 articles were analysed, of which $88.6 \%$ were empirical. Articles using a quantitative methodology accounted for $85.9 \%$ of the total and $97 \%$ of the empirical papers, illustrating that this is clearly the majority approach. In contrast, only a small number of articles used a qualitative approach or mixed methods.

The nine articles that referred to mixed methods had the following methodological characteristics (Table 6). As regards priority, six gave equal weight to the quantitative 
and qualitative parts of the study, while the remaining three prioritised one over the other (the predominant method being the quantitative approach). With respect to the implementation of data collection, two studies did so simultaneously while the remaining seven used a sequential strategy. The analysis of how priority and implementation were combined revealed two studies whose design was equal weight and simultaneous implementation (QUAL+QUAN), four designs based on equal weight and sequential data collection $(\mathrm{QUAL} \rightarrow \mathrm{QUAN})$ and three with different weight (once again in favour of the quantitative approach) and sequential implementation $($ qual $\rightarrow$ QUAN).

Finally, two main purposes were identified: development, in seven articles, and expansion in the remaining two.

Table 6

\section{Discussion and conclusions}

\subsection{Comparison of the journals}

The comparison of results is shown in Table 7 , which gives the main data for each journal in order to show the evidence from multiple cases to draw cross-case conclusion of this mixed methods research. This reveals a clear predominance of empirical studies (89.1\%) over theoretical papers (10.9\%). Addictive Behaviors is the journal which publishes, in line with its editorial policy, the most empirical articles, followed by Psicothema and the Journal of Organizational Behavior. It can also be seen that most of the articles are quantitative in nature (85.7\%), with only a small number of qualitative and mixed methods studies being published (1.7\% in each case). This comparison confirms that in recent years these journals in these areas of the behavioural sciences mainly publish empirical studies that are almost always conducted using a quantitative methodology.

Table 7 
As regards the studies that used both quantitative and qualitative methods, Table 8 shows the characteristics of these mixed designs, as well as their stated methodological purpose. In the Journal of Organizational Behavior a total of seventeen articles were identified, a design giving different weight to the two methods being slightly more common than the equal weight approach. Data were generally collected using a sequential strategy. As regards the stated purpose of using mixed methods all four categories (development, triangulation, complementarity and expansion) were represented in this journal. In Addictive Behaviors six mixed methods articles were identified, the most common design being one that gave equal weight to the two methods, combined with simultaneous data collection. The stated purposes were triangulation (which seeks corroboration and convergence between the two methods) and complementarity (which aims to elaborate, illustrate and clarify the results of one method through the findings of the other). Finally, a total of nine articles were found in the journal Psicothema, the most common design being one that gave equal weight to the quantitative and qualitative aspects, combined with a sequential data collection. The stated purposes of using mixed methods were mainly development (i.e. using the results of one method to help generate and apply the other method subsequently) and expansion (which involves broadening the research question by using different methods for its different components).

In summary, it seems that mixed methods research is still little known and/or used, as qualitative methods research in the behavioural science field. Furthermore, when this methodological approach is selected for a study, the research design seems to be a sequential equal weight mixed methods research design.

Table 8

This mixed methods multiple-case study research has had the potentiality to describe each single-case study first quantitatively and after qualitatively, letting us establish the comparison between cases in relation to their quantitative subunits of analysis (number of non empirical and empirical studies -quantitative, qualitative and mixed-), and within cases of each journal in relation to its qualitative subunits of analysis (observing main characteristics of mixed methods research articles published). These multiple evidences make the overall study more robust than a single-case study design, following "replication" logic similar to multiple experiments (Yin, 2003), in the sense that case- 
to-case operates as a generalization that could be understood as an accumulation of evidence to the population of articles published in reputable behavioural sciences journals (following Onwuegbuzie, 2003). Three literal replications were made, because journals selected had similar characteristics (field of knowledge, international recognition, they were peer-reviewed and they had reputation established by their impact factor index).

To conclude this section it should be noted that only one of the mixed methods studies that were identified in the three journals (namely, the paper by Challiol and Mignonac (2005) in the Journal of Organizational Behavior) cited a methodological study about mixed methods (specifically, the study by Greene, Caracelli and Graham [1989]). This suggests that the mixed methods approach is not very familiar to researchers in these areas of the behavioural sciences and, as such, its potential and the possibilities it offers in terms of the purposes discussed here may not be taken full advantage of.

\subsection{Recommendations and future research}

Conducting mixed methods research in the behavioural sciences may help to understand certain aspects of studies that have already been carried out in this and other fields. In this regard, Creswell, Plano Clark, Gutmann and Hanson (2003) point out that a central challenge for mixed methods research is the explicit clarification of several key aspects. Firstly, researchers should clearly identify the main purposes of using a mixed design that includes both quantitative and qualitative data. Furthermore, it is necessary to clarify the factors analysed in the present paper when determining the type of design. Thus, with respect to the issue of priority, researchers must clearly describe the decisions made when assigning the respective weight (equal or different) to the quantitative and qualitative parts, which could be reflected in the length and depth of the comments and discussions made regarding each of the approaches. In relation to the implementation of data collection, researchers should clearly specify whether the design is sequential or simultaneous. For example, if the design is sequential the two stages of data collection and analysis could be presented in separate sections, before integrating the findings in the discussion and/or conclusions of the paper. Given the complexity of 
these aspects, researchers may find it useful to present their results with the help of figures or visual models (Ivankova, Creswell and Stick, 2006).

It should also be remembered that although a particular design may be initially proposed for a given study, new aspects or ideas may emerge as the research progresses, and this could lead to the original design being modified. As such, researchers should be creative and not restrict themselves to pre-existing designs; indeed, they may even need to create new designs that are suitable for the research questions being considered. In this context, while sequential mixed designs usually have two parts they may be more complex and require three or more stages (Johnson and Onwuegbuzie, 2004; Teddlie and Tashakkori, 2006). Furthermore, the present research design typologies in the mixed methods approach could be still improved containing case study design research to attend the complexity of the combination of qualitative and quantitative methods in the same study, as a single-case study or as an instrumental (Onwuegbuzie \& Leech, 2009) or multiple-case study mixed methods research. In order to do a cross-case analyses and to improve, at least to some degree, the generalization through replication, although more must be done in this field of knowledge and others were mixed methods research are starting to be used as a new methodological option.

In our opinion it would be interesting to conduct further reviews covering both a broader time period and other journals so as to obtain a more detailed picture of how mixed methods research is being applied. Indeed, such research may help to promote the use of mixed methods in the behavioural sciences. At all events, researchers need to be aware of the extent to which this approach is accepted within their respective areas, and is being used by their colleagues. The present study has identified a number of mixed methods articles that could serve as a guide for future mixed methods studies.

\section{Declaration of Conflict Interests}

The authors declare no potential conflicts of interests with respect to the authorship and/or publication of this article.

\section{Financial Disclosure/Funding}

The authors received no financial support for the research and/or authorship of this article. 


\section{References}

Acosta, M.C., Eissenberg, T., Nichter, M., Balster, R.L., TERN (Tobacco Etiology Research Network): Characterizing early cigarette use episodes in novice smokers. Addictive Behaviors 33(1), 106-121 (2008)

Aragonés, J.I., Izurieta, C., Raposa, G.: Revisando el concepto de desarrollo sostenible en el discurso social. Psicothema 15(2), 221-226 (2003)

Arce, R., Fariña, F., Seijo, D.: Razonamientos judiciales en procesos de separación. Psicothema 17(1): 57-63 (2005)

Arce, R., Tortosa, F., Alfaro, E.: Veredictos y análisis del contenido de las deliberaciones de los tribunales de jueces y jurados en el contexto jurídico español. Psicothema 15(1), 127-135 (2003)

Bergman, M. (ed.): Advances in mixed methods research. Sage, London (2008)

Boyatzis, R.E.: Using tipping points of emotional intelligence and cognitive competencies to predict financial performance of leaders. Psicothema 18(Sup.1), 124-131 (2006)

Bradizza, C.M., Collins, R. L., Vincent, P.C., Falco, D.L.: It does the job: Young adults discuss their malt liquor consumption. Addictive Behaviors 31(9), 1559-1577 (2006)

Bryman, A.: Integrating quantitative and qualitative research: How is it done? Qualitative Research 6, 97-113 (2006)

Caldwell, S., Farmer, S., Fedor, D.: The influence of age on volunteer contributions in a nonprofit organization. Journal of Organizational Behavior 29: 311-333 (2008)

Challiol, H., K. Mignonac.: Relocation decision-making and couple relationships: a quantitative and qualitative study of dual-earner couples. Journal of Organizational Behavior 26, 247-274 (2005)

Creswell, J.: Research design. Qualitative, quantitative and mixed methods approaches, 2nd edn. Sage, Thousand Oaks, CA (2003)

Creswell, J.W., Fetters, M., Ivankova, N.V.: Designing a mixed methods study in primary care. Annals of Family Medicine 2(1), 7-12 (2004)

Creswell, J., Plano-Clark, V.: Designing and conducting mixed methods research. Sage, Thousand Oaks, CA (2007)

Creswell, J., Plano Clark, V., Gutmann, M., Hanson, W.: Advanced mixed methods research designs. In: Tashakkori, A., Teddlie, C. (eds.) Handbook of mixed methods in social \& behavioral research, pp. 209-240. Sage, Thousand Oaks, CA (2003) 
Donnelly, D., Quirin, J.: An extension of Lee and Mitchell's unfolding model of voluntary turnover. Journal of Organizational Behavior 27, 59-77 (2006)

Drach-Zahavy, A., Freund. A.: Team effectiveness under stress: A structural contingency approach. Journal of Organizational Behavior 28, 423-450 (2007)

Forthofer, M.: Status of mixed methods research in nursing. In: Tashakkori, A., Teddlie, C. (eds.) Handbook of mixed methods in social \& behavioral research, pp. 527-540. Sage, Thousand Oaks, CA (2003)

García, N., Fidalgo, R.: Diferencias en la conciencia de los procesos psicológicos de la escritura: mecánicos frente a substantivos y otros. Psicothema 15(1), 41-48 (2003)

Grandey, A., Dickter, D., Sin, H.: The customer is not always right: Customer aggression and emotion regulation of service employees. Journal of Organizational Behavior 25, 397-418 (2004)

Greene, J.: Mixed methods in social inquiry. Jossey-Bass, San Francisco, CA (2007)

Greene, J., Caracelli, V., Graham, W.: Toward a conceptual framework for mixedmethod evaluation designs. Educational Evaluation and Policy Analysis 11, 255-274 (1989)

Hanson, W., Creswell, J.W., Plano Clark, V.L., Petska, K., Creswell, J.D.: Mixed methods research designs in counseling psychology. Journal of Counseling Psychology 52, 224-35 (2005)

Hart, L., Smith, S., Swars, S., Smith, M.: An examination of research methods in mathematics education. Journal of Mixed Methods Research 3, 26-41 (2009)

Ivankova, N.V., Creswell, J.W., Stick. S.L.: Using mixed-methods sequential explanatory design: From theory to practice. Field Methods 18(1), 3-20 (2006)

Jick, T.: Mixing qualitative and quantitative methods: Triangulation in action. Administrative Science Quarterly 24, 602-611 (1979)

Johnson, B., Onwuegbuzie, A.: Mixed methods research: A research paradigm whose time has come. Educational Researcher 33(7), 14-26 (2004)

Lam, S., Dreher, G.: Gender, extra-firm mobility, and compensation attainment in the United States and Hong Kong. Journal of Organizational Behavior 25, 791-805 (2004)

Leech, N., Onwuegbuzie, A.J.: A typology of mixed methods research designs. Quality \& Quantity 43, 265-275 (2009) 
Leonard, J., Levine, D., Joshi, A.. Do birds of a feather shop together? The effects on performance of employees' similarity with one another and with customers. Journal of Organizational Behavior 25, 731-754 (2004)

Levy, O. The influence of top management team attention patterns on global strategic posture of firms. Journal of Organizational Behavior 26, 797-819 (2005)

Lievens, F., De Paepe, A.: An empirical investigation of interviewer-related factors that discourage the use of high structure interviews. Journal of Organizational Behavior 25, 29-46 (2004)

Lilius, J., Worline, M., Maitlis, S., Kanov, J., Dutton, J., Frost, P.: The contours and consequences of compassion at work. Journal of Organizational Behavior 29, 193$218(2008)$

Liu, C., Spector, P., Shi, L.: Cross-national job stress: a quantitative and qualitative study. Journal of Organizational Behavior 28: 209-239 (2007)

Moore, S., Grunberg, L., Greenberg, E.: A longitudinal exploration of alcohol use and problems comparing managerial and nonmanagerial men and women. Addictive Behaviors 28(4), 687-703 (2003)

Morgan, D.: Practical strategies for combining qualitative and quantitative methods: Applications to health research. Qualitative Health Research 8, 362-376 (1998)

Morse, J.: Approaches to qualitative-quantitative methodological triangulation. Nursing Research 40, 120-123 (1991)

Nembhard, I., Edmondson, A.: Making it safe: The effects of leader inclusiveness and professional status on psychological safety and improvement efforts in health care teams. Journal of Organizational Behavior 27, 941-966 (2006)

Niglas, K.: The combined use of qualitative and quantitative methods in educational research. Tallinn Pedagogical University Press, Tallinn (2004)

Nielsen, K., Randall, R., Albertsen, K.: Participants' appraisals of process issues and the effects of stress management interventions. Journal of Organizational Behavior 28, 793-810 (2007)

Nordqvist, C., Johansson, K., Lindqvist, K., Bendtsen, P.: Attitude changes among emergency department triage staff after conducting routine alcohol screening. Addictive Behaviors 31(2): 191-202 (2006)

Onwuegbuzie, A.J.: Effect sizes in qualitative research: a prolegomenon. Quality \& Quantity 37, 393-409 (2003) 
Onwuegbuzie, A.J., Johnson, R.B.: Mixed method and mixed model research. In: Johnson, R.B., Christensen, L.B. (eds.) Educational Research: Quantitative, Qualitative, and Mixed Approaches, pp. 408-431. Allyn and Bacon, Needham Heights, MA (2004)

Onwuegbuzie, A.J., Johnson, R.B., Collins, K.M.T.: Assessing legitimation in mixed research: a new framework. Quality \& Quantity (2009) doi: 10.1007/s11135-0099289-9

Onwuegbuzie, A.J., Leech, N.: Generalization practices in qualitative research: a mixed methods case study. Quality \& Quantity (2009) doi: 10.1007/s11135-009-9241-z

Onwuegbuzie, A.J., Teddlie, C.: A framework fro analyzing data in mixed methods research. In: Tashakkori, A., Teddlie, C. (eds.) Handbook of Mixed Methods in Social and Behavioral Research, pp. 351-383. Sage, Thousand Oaks, CA (2003)

Ostroff, C., Shin, Y., Kinicki, A.: Multiple perspectives of congruence: relationships between value congruence and employee attitudes. Journal of Organizational Behavior 26, 591-623 (2005)

Plano Clark, V. L., Garrett, A.L., Leslie-Pelecky, D.L.: Applying three strategies for integrating quantitative and qualitative databases in a mixed methods study of a non-traditional graduate education program. Field Methods 22(2), 154-174 (2010)

Plano Clark, V.L.: Cross-disciplinary analysis of the use of mixed methods in physics education research, counseling psychology, and primary care. (Doctoral dissertation, University of Nebraska-Lincoln, 2005). Dissertation Abstracts International 66, 02A (2005)

Plano Clark, V. L., Huddleston-Casas, C. A., Churchill, S.L., O’Neil Green, D., Garrett, A.L.: Mixed methods approaches in family science research. Journal of Family Issues 29, 1543-66 (2008)

Patterson, M., West, M., Wall. T.: Integrated manufacturing, empowerment, and company performance. Journal of Organizational Behavior 25, 641-665 (2004)

Pérez-González, A., G. Williams: Programa integral para la enseñanza de habilidades a niños con autismo. Psicothema 17(2), 233-244 (2005)

Powell, H., Mihalas, S., Onwuegbuzie, A., Suldo, S., Daley, C.: Mixed methods research in school psychology: A mixed methods investigation of trends in the literature. Psychology in the Schools 45(4), 291-309 (2008)

Rafaeli, A.: Sense-making of employment: On Whether and why people read employment advertising. Journal of Organizational Behavior 27, 747-770 (2006) 
Rallis, S., Rossman. G.: Mixed methods in evaluation contexts: A pragmatic framework. In: Tashakkori, A., Teddlie, C. (eds.) Handbook of mixed methods in social \& behavioral research, pp. 491-512. Sage, Thousand Oaks, CA (2003)

Rocco, T., Bliss, L., Gallagher, S., Perez-Prado, A., Alacaci, C., Dwyer, W., Fine, J., Pappamihiel, E.: The pragmatic and dialectical lenses: Two views of mixed methods use in education. In: Tashakkori, A., Teddlie, C. (eds.) Handbook of mixed methods in social \& behavioral research, pp. 595-615. Sage, Thousand Oaks, CA (2003)

Rodríguez, G., Triana, B., Hernández, M.H.: La experiencia familiar y la atribución de roles parentales. Psicothema 17 (3), 363-369 (2005)

Sale, J.E.M., Brazil, K.: A strategy to identify critical appraisal criteria for primary mixed-method studies. Quality \& Quantity 38, 351-365 (2004)

Stotts, A.L., Mooney, M.E., Sayre, S.L., Novy, M., Schmitz, J.M., Grabowski, J.: Illusory predictors: Generalizability of findings in cocaine treatment retention research. Addictive Behaviors 32(12), 2819-2836 (2007)

Tashakkori, A., Teddlie, C.: Mixed methodology. Combining qualitative and quantitative approaches. Sage, Thousand Oaks, CA (1998)

Tashakkori, A., Teddlie, C. (eds.): Handbook of mixed methods in social \& behavioral research. Sage, Thousand Oaks, CA (2003)

Teddlie, C., Tashakkori, A.: A general typology of research designs featuring mixed methods. Research in the Schools 13, 12-28 (2006)

Teddlie, C., Tashakkori, A. (eds.): Foundations of mixed methods research: Integrating quantitative and qualitative techniques in the social and behavioural sciences. Sage, Thousand Oaks, CA (2009)

Terry, P., Wright, K.A.: Self-reported driving behaviour and attitudes towards driving under the influence of cannabis among three different user groups in England. Addictive Behaviors 30(3), 619-623 (2005)

Varela, J., Rial, A., García, E.: Presentación de una escala de satisfacción con los servicios sanitarios de atención primaria. Psicothema 15(5), 656-661 (2003)

Villar, F., Triadó, C., Solé, C., Osuna, M.J.: Patrones de actividad cotidiana en personas mayores: ¿es lo que dicen hacer lo que desearían hacer? Psicothema 18(1), 149-155 (2006)

Wright, R.: Mapping cognitions to better understand attitudinal and behavioural responses in appraisal research. Journal of Organizational Behavior 25, 339-374 (2004) 
Yin, R.K.: Applications of Case Study Research. Sage, Newbury Park, CA (1993)

Yin, R.K.: Case study research: designs and methods, 3rd edn. Sage, Thousand Oaks, CA (2003) 
Table 1. Articles published in the Journal of Organizational Behavior (2003-2008)

\begin{tabular}{|c|c|c|c|c|c|c|}
\hline \multirow[b]{2}{*}{ Year } & \multirow[b]{2}{*}{$\begin{array}{c}\text { Number of } \\
\text { articles }\end{array}$} & \multirow[b]{2}{*}{$\begin{array}{c}\text { Number of } \\
\text { non-empirical } \\
\text { articles }\end{array}$} & \multicolumn{4}{|c|}{ Empirical articles } \\
\hline & & & $\begin{array}{c}\text { Number of } \\
\text { empirical } \\
\text { articles }\end{array}$ & $\begin{array}{l}\text { Number of } \\
\text { quantitative } \\
\text { articles }\end{array}$ & $\begin{array}{c}\text { Number of } \\
\text { qualitative } \\
\text { articles }\end{array}$ & $\begin{array}{c}\text { Number of } \\
\text { mixed articles }\end{array}$ \\
\hline 2003 & 50 & 10 & 40 & 40 & 0 & 0 \\
\hline 2004 & 47 & 4 & 43 & 35 & 2 & 6 \\
\hline 2005 & 50 & 18 & 32 & 28 & 1 & 3 \\
\hline 2006 & 56 & 15 & 41 & 33 & 5 & 3 \\
\hline 2007 & 55 & 20 & 35 & 27 & 5 & 3 \\
\hline 2008 & 60 & 20 & 40 & 34 & 4 & 2 \\
\hline Total & 318 & 87 & 231 & 197 & 17 & 17 \\
\hline
\end{tabular}


Table 2. Characteristics of the mixed methods studies published in the Journal of Organizational Behavior

\begin{tabular}{|c|c|c|c|c|}
\hline Article & Purpose & Priority & Implementation & Design \\
\hline Lievens \& De Paepe (2004) & Triangulation & Equal & Simultaneous & QUAL+QUAN \\
\hline Wright (2004) & Development & QUAN & Sequential & qual $\rightarrow$ QUAN \\
\hline Grandey et al. (2004) & Development & QUAN & Sequential & qual $\rightarrow$ QUAN \\
\hline Patterson et al. (2004) & Development & Equal & Sequential & $\mathrm{QUAL} \rightarrow \mathrm{QUAN}$ \\
\hline Leonard et al. (2004) & Complementarity & QUAN & Sequential & QUAN $\rightarrow$ qual \\
\hline Lam \& Dreher (2004) & Complementarity & QUAN & Sequential & QUAN $\rightarrow$ qual \\
\hline Challiol \& Mignonac (2005) & Triangulation & Equal & Simultaneous & QUAL+QUAN \\
\hline Ostroff et al. (2005) & Development & QUAN & Sequential & qual $\rightarrow$ QUAN \\
\hline Levy (2005) & Development & QUAN & Sequential & qual $\rightarrow$ QUAN \\
\hline Donnelly \& Quirin (2006) & Triangulation & Equal & Simultaneous & QUAL+QUAN \\
\hline Rafaeli (2006) & Expansion & Equal & Simultaneous & QUAL+QUAN \\
\hline Nembhard \& Edmondson (2006) & Development & QUAN & Sequential & qual $\rightarrow$ QUAN \\
\hline Liu et al. (2007) & Complementarity & Equal & Sequential & $\mathrm{QUAN} \rightarrow \mathrm{QUAL}$ \\
\hline Drach-Zahavy \& Freund (2007) & Development & QUAN & Sequential & qual $\rightarrow$ QUAN \\
\hline Nielsen et al. (2007) & Complementarity & QUAN & Sequential & QUAN $\rightarrow$ qual \\
\hline Lilius et al. (2008) & Complementarity & Equal & Sequential & $\mathrm{QUAN} \rightarrow \mathrm{QUAL}$ \\
\hline Caldwell et al. (2008) & Development & QUAN & Sequential & qual $\rightarrow$ QUAN \\
\hline
\end{tabular}


Table 3. Articles published in Addictive Behaviors (2003-2008)

\begin{tabular}{ccccccc}
\hline \multirow{2}{*}{ Year } & $\begin{array}{c}\text { Number of } \\
\text { articles }\end{array}$ & $\begin{array}{c}\text { Number of } \\
\text { non-empirical } \\
\text { articles }\end{array}$ & $\begin{array}{c}\text { Number of } \\
\text { empirical } \\
\text { articles }\end{array}$ & $\begin{array}{c}\text { Number of } \\
\text { quantitative } \\
\text { articles }\end{array}$ & $\begin{array}{c}\text { Number of } \\
\text { qualitative } \\
\text { articles }\end{array}$ & $\begin{array}{c}\text { Number of } \\
\text { mixed articles }\end{array}$ \\
\hline 2003 & 135 & 6 & 129 & 126 & 2 & 1 \\
2004 & 191 & 12 & 179 & 179 & 0 & 0 \\
2005 & 139 & 4 & 135 & 134 & 0 & 1 \\
2006 & 155 & 8 & 147 & 143 & 2 & 2 \\
2007 & 188 & 7 & 181 & 179 & 1 & 1 \\
2008 & 124 & 8 & 116 & 115 & 0 & 6 \\
Total & 932 & 45 & 887 & 876 & 5 & 1 \\
\hline
\end{tabular}


Table 4. Characteristics of the mixed methods studies published in Addictive Behaviors

\begin{tabular}{lcccc}
\hline \multicolumn{1}{c}{ Article } & Purpose & Priority & Implementation & Design \\
\hline Moore et al. (2003) & Complementarity & Equal & Simultaneous & QUAL+QUAN \\
Terry \& Wright (2005) & Triangulation & Equal & Simultaneous & QUAL+QUAN \\
Nordqvist et al. (2006) & Triangulation & Equal & Simultaneous & QUAL+QUAN \\
Bradizza et al. (2006) & Triangulation & Equal & Simultaneous & QUAL+QUAN \\
Stotts et al. (2007) & Complementarity & Equal & Sequential & QUAL $\rightarrow$ QUAN \\
Acosta et al. (2008) & Complementarity & QUAN & Sequential & QUAN $\rightarrow$ qual \\
\hline
\end{tabular}


Table 5. Articles published in Psicothema (2003-2008)

\begin{tabular}{|c|c|c|c|c|c|c|}
\hline \multirow[b]{2}{*}{ Year } & \multirow[b]{2}{*}{$\begin{array}{c}\text { Number of } \\
\text { articles }\end{array}$} & \multirow[b]{2}{*}{$\begin{array}{c}\text { Number of } \\
\text { non-empirical } \\
\text { articles }\end{array}$} & \multicolumn{4}{|c|}{ Empirical articles } \\
\hline & & & $\begin{array}{c}\text { Number of } \\
\text { empirical } \\
\text { articles }\end{array}$ & $\begin{array}{c}\text { Number of } \\
\text { quantitative } \\
\text { articles }\end{array}$ & $\begin{array}{l}\text { Number of } \\
\text { qualitative } \\
\text { articles }\end{array}$ & $\begin{array}{c}\text { Number of } \\
\text { mixed articles }\end{array}$ \\
\hline 2003 & 101 & 12 & 89 & 82 & 3 & 4 \\
\hline 2004 & 101 & 17 & 84 & 80 & 4 & 0 \\
\hline 2005 & 106 & 14 & 92 & 87 & 2 & 3 \\
\hline 2006 & 152 & 15 & 137 & 134 & 1 & 2 \\
\hline 2007 & 102 & 13 & 89 & 89 & 0 & 0 \\
\hline 2008 & 146 & 10 & 136 & 136 & 0 & 0 \\
\hline Total & 708 & 81 & 627 & 608 & 10 & 9 \\
\hline
\end{tabular}


Table 6. Characteristics of the mixed methods studies published in Psicothema

\begin{tabular}{|c|c|c|c|c|}
\hline Article & Purpose & Priority & Implementation & Design \\
\hline García \& Fidalgo (2003) & Development & Equal & Sequential & QUAL $\rightarrow$ QUAN \\
\hline Arce et al. (2003) & Development & Equal & Sequential & $\mathrm{QUAL} \rightarrow \mathrm{QUAN}$ \\
\hline Aragonés et al. (2003) & Development & Equal & Sequential & $\mathrm{QUAL} \rightarrow \mathrm{QUAN}$ \\
\hline Mallou et al. (2003) & Development & QUAN & Sequential & qual $\rightarrow$ QUAN \\
\hline Arce et al. (2005) & Development & Equal & Sequential & QUAL $\rightarrow$ QUAN \\
\hline $\begin{array}{l}\text { Pérez-González \& Williams } \\
\text { (2005) }\end{array}$ & Expansion & Equal & Simultaneous & QUAL+QUAN \\
\hline Rodríguez et al. (2005) & Development & QUAN & Sequential & qual $\rightarrow$ QUAN \\
\hline Boyatzis (2006) & Development & QUAN & Sequential & qual $\rightarrow$ QUAN \\
\hline Villar et al. (2006) & Expansion & Equal & Simultaneous & QUAL+QUAN \\
\hline
\end{tabular}


Table 7. Comparison of the articles published in the journals analysed (2003-2008)

\begin{tabular}{ccccccc}
\hline \multirow{2}{*}{ Journals } & $\begin{array}{c}\text { Total number } \\
\text { of articles }\end{array}$ & $\begin{array}{c}\text { Number of } \\
\text { non-empirical } \\
\text { articles }\end{array}$ & $\begin{array}{c}\text { Number of } \\
\text { empirical } \\
\text { articles }\end{array}$ & $\begin{array}{c}\text { Number of } \\
\text { quantitative } \\
\text { articles }\end{array}$ & $\begin{array}{c}\text { Number of } \\
\text { qualitative } \\
\text { articles }\end{array}$ & $\begin{array}{c}\text { Number of } \\
\text { mixed articles }\end{array}$ \\
\hline JOB & 318 & $87(27.4)$ & $231(72.6)$ & $197(62)$ & $17(5.3)$ & $17(5.3)$ \\
AB & 932 & $45(4.8)$ & $887(95.2)$ & $876(94)$ & $5(0.5)$ & $6(0.7)$ \\
Psicothema & 708 & $81(11.4)$ & $627(88.6)$ & $608(85.9)$ & $10(1.4)$ & $9(1.3)$ \\
TOTAL & 1958 & $213(10.9)$ & $1745(89.1)$ & $1681(85.7)$ & $32(1.7)$ & $32(1.7)$
\end{tabular}

The numerical values inside the boxes are absolute frequencies and the values in parentheses are the percentage derived from the total in each case. 
Table 8. Characteristics of the mixed methods studies analysed (2003-2008)

\begin{tabular}{lccc}
\hline & & Journals & \\
\cline { 2 - 4 } & JOB (17) & AB (6) & \\
\hline Designs & $7(41.2)$ & $5(83.3)$ & $6(66.7)$ \\
Equal weight & $10(58.8)$ & $1(17.6)$ & $3(33.3)$ \\
Different weight & $4(23.5)$ & $4(66.7)$ & $2(22.2)$ \\
Simultaneous & $13(76.5)$ & $2(3.33)$ & $7(77.8)$ \\
Sequential & $3(17.6)$ & $3(50)$ & $0(0)$ \\
\hline Purpose & $5(29.4)$ & $3(50)$ & $0(0)$ \\
Triangulation & $8(47.1)$ & $0(0)$ & $7(77.8)$ \\
Complementarity & $1(5.9)$ & $0(0)$ & $2(22.2)$ \\
Development & & & \\
Expansion & & & \\
\hline
\end{tabular}

The numerical values inside the boxes are absolute frequencies and the values in parentheses are the percentage derived from the total in each case. 